\title{
АНТИБАКТЕРИАЛЬНАЯ ТЕРАПИЯ ГНОЙНО-НЕКРОТИЧЕСКИХ ОСЛОЖНЕНИЙ СИНДРОМА ДИАБЕТИЧЕСКОЙ СТОПЫ
}

\author{
(С Курлаев П.П. , Гриценко В.А. ${ }^{2}$, Белозерцева Ю.П. ${ }^{1}$
}

${ }^{1}$ Кафедра общей хирургии Оренбургского государственного медицинского университета, Оренбург; 2 лаборатория клеточного симбиоза Института клеточного и внутриклеточного симбиоза Уральского отделения Российской академии наук, Оренбург

E-mail: vag59@mail.ru

В обзоре рассматривается проблема выбора эффективного антибиотика для стартовой и целенаправленной противомикробной терапии гнойно-некротических осложнений синдрома диабетической стопы. Показано, что эмпирическая антибактериальная терапия должна проводиться с учетом предшествующего лечения, клинических данных, существующих клинических, национальных и международных рекомендаций, а также опираясь на данные локального бактериологического мониторинга и принимая во внимание возможность влияния антибиотиков (стимулирование/угнетение) на способность микроорганизмов образовывать биопленки и персистировать в организме. Обосновано определять чувствительность к антибиотикам 10 выделенных чистых культур микроорганизмов одного вида и отдавать предпочтение антибиотику, к которому восприимчивы все выделенные клоны этого вида бактерий. Использование антибиотика, подобранного по предложенной методике, позволяет санировать очаг гнойного воспаления в короткие сроки и уменьшить число высоких ампутаций в 2 раза.

Ключевые слова: синдром диабетической стопы, гнойно-некротические осложнения, выбор антибиотика.

\section{ANTIBACTERIAL THERAPY OF PURULENT-NECROTIC COMPLICATIONS OF DIABETIC FOOT SYNDROME \\ Kurlaev P.P. ${ }^{l}$, Gritsenko V.A. ${ }^{2}$, Belozertseva Yu.P. ${ }^{l}$}

${ }^{1}$ Department of General Surgery of Orenburg State Medical University, Orenburg; ${ }^{2}$ Laboratory of Cell Symbiosis of Institute of Cellular and Intracellular Symbiosis of Ural Branch of Russian Academy of Sciences, Orenburg

The review considers the problem of choosing an effective antibiotic for starting and purposeful antimicrobial therapy of purulent-necrotic complications of diabetic foot syndrome. It is shown that empirical antibacterial therapy should be carried out taking into account the previous treatment, clinical data, existing clinical, national and international recommendations, as well as based on the data of local bacteriological monitoring, and taking into account the possibility of the influence of antibiotics (stimulation/inhibition) on the ability of microorganisms to form biofilms and persist in the body. It is proposed to determine the sensitivity to antibiotics of 10 isolated pure cultures of microorganisms of the same species, and to give preference to the antibiotic, to which all isolated clones of this type of bacteria are susceptible. The use of an antibiotic selected according to the proposed technique allows sanitizing the focus of purulent inflammation in a short time and reducing the number of high amputations by 2 times.

Keywords: diabetic foot syndrome, purulent-necrotic complications, antibiotic choice.

Оптимизация лечения гнойно-некротических осложнений синдрома диабетической стопы (СДС) до сих пор сохраняет свою актуальность, поскольку сахарный диабет (СД) остается широко распространенной патологией, при которой часто развиваются инфекционно-воспалительные процессы, в том числе в области нижних конечностей, нередко требующие проведения ампутации на уровне бедра или голени $[1,17]$.

Вне зависимости от формы СДС (ишемическая, нейропатическая, смешанная) в организации комплексного лечения гнойных ран в области стоп, наряду с хирургическим вмешательством (обработка раневого дефекта, реконструктивные операции на сосудах для восстановления адекватного кровотока и др.), одно из основных мест принадлежит противомикробной терапии, эффективность которой во многом зависит от правиль- ного выбора антибиотика, осуществляемого в клинической практике зачастую эмпирически, что не всегда позволяет купировать течение инфекции и ухудшает прогноз как по сохранению конечности, так и жизни больного $[8,47]$. Вероятность успеха при назначении антибиотиков «вслепую» (эмпирически) не превышает $50-60 \%[23,25]$.

Определяющими в выборе стартового противомикробного средства, позволяющего повысить результативность управления инфекцией, являются данные локального (внутрибольничного) микробиологического мониторинга, отражающие то, какие микроорганизмы изолировались в подобных случаях от больных в конкретном лечебном учреждении ранее и к каким антибиотикам они были чувствительны [9, 27, 30, 46]. 
Ряд авторов сообщают, что в большинстве наблюдений этиологический фактор был представлен монофлорой $[3,14,30]$. Так, по данным С.Д. Шаповала с соавт. [37], у $80 \%$ больных СД из ран нижних конечностей изолировали микроорганизмы 23 разных видов, но в виде моноинфекции, и только в каждом пятом случае микрофлора была смешанной. По сведениям других авторов, при гнойно-некротических осложнениях СДС более чем в $90 \%$ случаев выделяются микробные аэробно-анаэробные ассоциации, включающие от 2 до 11 видов микроорганизмов [6-8, 34]. Такие диаметрально противоположные характеристики микрофлоры раневых дефектов при СДС, возможно, обусловлены тем, что отдельными авторами анализировались микробиологические параметры у групп пациентов с разными формами СДС и/или без учета особенностей течения гнойного процесса.

В то же время известно, что видовой спектр микроорганизмов, участвующих в развитии гнойных процессов в области стопы у пациентов с СД, зависит от многих факторов: формы СДС, длительности течения раневого процесса, глубины поражения, наличия предшествовавшего лечения антибиотиками и др. Так, при нейропатической форме СДС чаще (более 70\% случаев) выделяется золотистый стафилококк, в том числе в ассоциации с Klebsiella pneumoniae и/или Enterococcus faecalis, а при недостаточности артериального кровообращения (ишемическая форма СДС) возрастает доля грамотрицательной микрофлоры (до $52 \%)$, представленной псевдомонадами и энтеробактериями, включая эшерихии, клебсиеллы и др. [25, 42]. Однако по некоторым данным, четкой корреляции между видами возбудителей и различными формами СДС не просматривается [8]. При поверхностных поражениях чаще изолируются стафилококки и стрептококки, тогда как более глубокое расположение гнойнонекротического процесса характеризуется полимикробной микрофлорой с присоединением энтеробактерий. Длительно незаживающие язвы на фоне продолжительной антибактериальной терапии нередко контаминируются метициллинрезистентным $S$. aureus (MRSA), а при гангрене - облигатными анаэробами $[7,31]$.

По-видимому, выделение из раневого дефекта тех или иных микроорганизмов (в моноварианте или в составе микробных ассоциаций) существенно зависит не только от формы СДС и характера течения гнойного процесса, но и от места забора материала для бактериологического исследования (поверхностные или глубокие слои раны), качества транспортной среды, условий транспортировки образцов (соблюдение температурного режима), срока их доставки в лаборато- рию и используемых сред и технологий (аэробное/анаэробное) культивирования.

Для получения достоверной информации об инициирующей микрофлоре наиболее оптимальным считается использование для посева биоптата из глубоких слоев раны, а при остеомиелите изучение образца кости $[16,26,31,38,41,44]$. Для доставки материала желательно пользоваться официнальными транспортными средами, а максимально быстрое исследование образцов значительно повышает точность анализа [31].

Подчеркнем, что, по данным большинства авторов, основными возбудителями при гнойнонекротических осложнениях СДС являются: Staphylococcus aureus, S. epidermidis, Enterococcus faecalis, Pseudomonas aeruginosa, Escherichia coli и Acinetobacter baumannii [3, 5, 14, 30, 37]. Однако первенство среди патогенов, обусловливающих развитие воспаления, сохраняется за золотистым стафилококком. Его выделяют или в монокульту$\mathrm{pe}$, или в ассоциации с другими микроорганизмами в $20-65 \%$ наблюдений $[3,5,8,9,14,30,37]$. По результатам нашей клиники в 2005-2013 гг., S. aureus высевали в 30,5-53,2\% случаев, а коагулазоотрицательные стафилококки в 11,8-20,7\% наблюдений [4].

Очевидно, длительное паразитирование возбудителей в раневом дефекте и низкая эффективность эмпирической противомикробной терапии при СДС могут быть объяснены в основном 3 обстоятельствами: склонностью бактерий образовывать биопленки на раневой поверхности, их способностью ингибировать эффекторные механизмы иммунитета человека, а также высокой устойчивостью клинических штаммов микроорганизмов к антибиотикам.

В результате многочисленных исследований установлено, что в $60-90 \%$ наблюдений на раневой поверхности формируются бактериальные биопленки, которые в 100-1000 раз снижают чувствительность микрофлоры к антибиотикам [2, $11,20,22,24,32,40,48-50]$. Положительные результаты в борьбе с биопленочными формами бактерий при лечении гнойно-некротических осложнений СДС получены при обработке ран гидрохирургической системой VersaJet ${ }^{\circledR}$ в сочетании с комбинированной антибактериальной терапией $[18,35]$. Кроме того, показано, что степень формирования биопленок микроорганизмами снижается при использовании кларитромицина и азитромицина (возможно, и иных антибиотиков) $[19,35]$, а также при местном применении ципрофлоксацина в сочетании с окситоцином [12].

Вместе с тем известно, что тяжесть и продолжительность инфекционного процесса во многом определяются способностью бактериальных пато- 
генов инактивировать факторы естественной резистентности макроорганизма (лизоцим, система комплемента, лейко- и тромбодефенсины, иммуноглобулины и др.) $[10,39]$. Эти свойства микроорганизмов академиком О.В. Бухариным расцениваются как факторы персистенции, препятствующие процессам элиминации бактерий из очага воспаления и позволяющие им длительно в нем паразитировать, потенцируя неблагоприятное (продолжительное) течение инфекционно-воспалительных процессов [10]. Способность бактерий персистировать в гнойных ранах снижается при местном применении окситоцина, облучении гелий-неоновым лазером и электромагнитными волнами крайне высокой частоты (КВЧ-терапия) [21]. Здесь же заметим, что разные антибиотики в суббактерицидных (суббактериостатических) концентрациях могут разнонаправлено влиять на персистентные характеристики бактерий, подавляя или стимулируя их, либо не оказывая на них никакого эффекта (индифферентность) [36], что практически не учитывается при выборе препаратов для проведения антимикробной терапии.

С другой стороны, многие клинические изоляты бактерий, выделяемые из раневых дефектов при СДС, проявляют феномен резистентности к основным антибактериальным препаратам [37]. В частности, у 40-60\% пациентов с СДС наблюдается инфицирование раны штаммами MRSA [9, $30,31,37]$, у 30-70\% больных из раневого дефекта выделяются метициллинрезистентные $S$. ерidermidis (MRSE) [9, 30]. Ухудшению течения заболевания и росту летальности способствует контаминация раны S. aureus, P. aeruginosa, E. coli, K. pneumoniae, Proteus spp. и Acinetobacter spp., которые в 45-100\% случаев обладают резистентностью к $\beta$-лактамным антибиотикам $[29,30,37$, 45]. Следует помнить, что наиболее активными препаратами против штаммов MRSA, являются даптомицин, ванкомицин, тейкопланин, тайгециклин, а в отношении бактерий, производящих бета-лактамазы расширенного спектра действия, эффективны карбапенемы (имипенем/циластатин и меропенем) [37].

В большинстве случаев при назначении стартовой антибактериальной терапии хирурги ориентируются на существующие стандарты по проведению этиотропного лечения гнойнонекротических осложнений СДС. Так, в клинических рекомендациях под редакцией И.И. Дедова по курации больных СД при наличии гнойнодеструктивных процессов на стопе отмечено, что при нейропатической форме СДС с язвой стопы показано применение цефалоспоринов II генерации, фторхинолонов, метронидазола, клиндамицина, даптомицина [1]. В российских национальных рекомендациях предложено пациентам с СД при наличии гнойно-деструктивных процессов на стопе назначать антибиотики с учетом степени тяжести заболевания, места проведения терапии (поликлиника или стационар), с выделением групп пациентов, получавших и не получавших антибиотики в амбулаторном порядке. Кроме того, тактика эмпирической антибактериальной терапии корректируется при развитии остеомиелита, полиорганной недостаточности, септического шока. В общей сложности предложено использовать 37 наименований антибиотиков [33].

В международных стандартах по выбору антибиотика при СДС подчеркивается, что адекватная и своевременно начатая терапия в $85 \%$ случаев позволяет избежать калечащей операции [13]. Вместе с нормализацией метаболического статуса и хирургической обработкой гнойного очага, большое значение придается рациональной антибактериальной терапии. В случаях легкого течения инфекции предлагается назначать антибиотики, обладающие активностью в отношении грамположительных кокков - амоксициллин/клавуланат, клиндамицин, цефалексин или цефазолин, а при наличии грамотрицательной микрофлоры (или подозрении на нее) - левофлоксацин, возможно в комбинации с клиндамицином. Выраженные системные проявления инфекции являются основанием для госпитализации пациентов и использования цефазолина, оксациллина или клиндамицина. При высоком риске инфицирования раны MRSA применяют ванкомицин или линезолид. Стартовую антибактериальную терапию рекомендуется начинать с препаратов, активных в отношении $S$. aureus, бетагемолитических стрептококков, энтеробактерий и некоторых анаэробов. В отношении последних предполагается использование цефамицинов (цефокситин, цефотетан). При тяжелой инфекции проводится деэскалационная антибиотикотерапия с ведением цефоперазона/сульбактама и карбапенемов [13]. В то же время A.W. Karchmer не peкомендует в качестве эмпирической терапии использовать цефокситин и цефотетан из-за недостаточной эффективности в отношении отдельных патогенов [43].

По данным Б.С. Брискина, от 85,7 до 100\% микроорганизмов проявляли чувствительность к амикацину, левофлоксацину, моксифлоксацину, цефотаксину, цефтазидиму, цефтриаксону, цефепиму, ванкомицину, амоксиклаву, клиндамицину, метронидазолу, тиенаму [8].

B.M. Бенсман рекомендует активнее назначать антибиотики резерва, к которым бактериальная флора пациентов не успела утратить чувствительности [6]. Из этих соображений предпочтение надо отдавать применению цефалоспоринов третьего или четвертого поколения (цефотаксим, це- 
фтриаксон, цефпиром, цефепим, цефоперазонсульбактам), фторхинолонов второго поколения (левофлоксацин, моксифлоксацин, спарфлоксацин) и защищенных бета-лактамных антибиотиков (амоксиклав, уназин, тазоцин, тикарциллинклавуланат). При подозрении на неклостридиально-анаэробную инфекцию к комбинации цефалоспоринов и фторхинолонов добавляют метронидазол или клиндамицин. В случаях септического течения гнойных осложнений СДС применяют имипенем, меропенем, тиенам в сочетании с метронидазолом или клиндамицином.

Таким образом, для этиотропной терапии гнойных осложнений СДС рекомендовано достаточно большое количество антибиотиков, и выбрать тот единственный и эффективный препарат весьма затруднительно, тем более, что по некоторым рандомизированным клиническим исследованиям не было выявлено антибиотика, который имел бы превосходство над другими антибактериальными препаратами $[16,24,45]$. Повидимому, предпочтение следует отдавать противомикробному средству, опираясь на данные локального бактериологического мониторинга.

Более эффективным считается персонифицированный подход к выбору антибиотиков для целенаправленной противомикробной терапии конкретного больного с СДС, что предполагает выделение у него из раневого дефекта микроорганизма или микроорганизмов (при наличии микробных ассоциаций), его/их видовую идентификацию и определение чувствительности к антимикробным средствам с назначением адекватного препарата или при необходимости их комбинации. Предпочтение отдается ступенчатой или деэскалационной схемам лечения [5, 26, 27].

Обычно чувствительность к антибиотикам определяется лишь у одной выделенной чистой типичной культуры (штамма) микроорганизма конкретной видовой принадлежности без учета возможности присутствия в исследуемом материале нескольких клоновых линий (вариантов) бактерий одного вида, которые могут отличаться друг от друга не только патогенными свойствами (гемолитическая активность, наличие капсулы, продукция токсинов, биопленкообразование и др.), но и разной резистентностью/чувствительностью к определенным группам антибиотиков $[15,31,37]$.

Результаты наших исследований свидетельствуют, что у больных с СДС в гнойной ране возбудители одного вида могут быть представлены 1 (одной), 2 (двумя) и 3 (тремя) клоновыми линиями бактерий, которые отличались друг от друга по спектрам чувствительности к антимикробным препаратам (по антибиотикограмме) и которые наиболее оптимально и эффективно выявляются при определении антибиотикочувствительности у 10 выделенных чистых культур микроорганизмов [28]. Тестирование меньшего количества (2-8) чистых культур бактерий одного вида не позволяет обнаружить все имеющиеся в ране клоновые линии микроорганизмов конкретного вида, а увеличение количества исследуемых чистых культур бактерий до 12 и 14 не изменяет результаты тестирования. Лечение больных с гнойными осложнениями СДС с применением антимикробных препаратов, к которым чувствительны все клоновые линии одного вида микроорганизма, более эффективно, чем при выборе антибиотиков рутинным способом. Такой подход к определению чувствительности микрофлоры позволяет у больных с гнойными осложнениями нейропатической формы СДС добиться на 3-5 сутки лечения нормализации температуры тела у большей доли пациентов (83,3 против $68,3 \%$ ), количества лейкоцитов в периферической крови $(86,7$ против $51,7 \%)$, прекращения образования гноя в ране $(83,3$ против $41,7 \%)$ и высеваемости микрофлоры из ран (90,0 против 43,3\%), в 2 раза уменьшить число случаев высоких ампутаций конечностей (13,3 против 26,7\%).

Таким образом, при проведении антимикробной терапии гнойно-некротических осложнений СДС необходимо учитывать много факторов, способных оказывать существенное влияние на ее эффективность, в связи с чем выбор оптимального антибактериального препарата (или препаратов) является достаточно сложной задачей. Очевидно, при назначении стартовой терапии он должен базироваться на национальных и международных рекомендациях с учетом особенностей клинического течения заболевания у конкретного больного, опираться на данные локального (внутрибольничного) микробиологического мониторинга по антибиотикорезистентности приоритетных возбудителей патологического процесса. Кроме того, следует принимать во внимание возможность влияния отдельных антибиотиков (стимулирование/угнетение) на персистентный потенциал микроорганизмов. Однако в любом случае такой выбор лекарственных препаратов фактически остается эмпирическим.

Более надежным и эффективным является персонифицированный (пациент-ориентированный) подход, предусматривающий выделение из раневого дефекта у конкретного больного чистой культуры (а при наличии микробной ассоциации - нескольких культур разных видов) микроорганизмов с последующим определением ее (их) чувствительности к антибиотикам, по результатам которого осуществляется отбор эффективных препаратов. Однако и при указанном традиционном способе микробиологического исследования 
существует вероятность не получить желаемого терапевтического результата, так как не учитывается возможность колонизации раны разными клоновыми линиями микроорганизмов одного вида, отличающихся друг от друга по спектрам антибиотикорезистентности. В то же время эффективность лечения значительно повышается, если отбор оптимального препарата осуществляется по результатам тестирования на чувствительность к антибиотикам не 1, а 10 выделенных чистых культур микроорганизмов каждого вида. При этом предпочтение следует отдавать антибиотику (или комбинации препаратов), к которому (к которым) восприимчивы все выделяемые из раны клоны бактерий.

Представленный обзор литературы отражает современные подходы к проведению антибактериальной терапии гнойно-некротических осложнений при синдроме диабетической стопы и нацеливает на их совершенствование для повышения эффективности оказания медицинской помощи пациентам с указанной патологией.

Работа выполнена по теме из Плана НИР ИКВС УрО РАН «Эндогенные бактериальные инфекции: возбудители, факторы риска, биомаркеpbl, разработка алгоритмов диагностики, лечения и профилактики», № гос. рег. 116021510075 ; и в рамках Комплексной программы фундаментальных исследований УрО РАН, проект № 18-7-8-26.

\section{КОНФЛИКТ ИНТЕРЕСОВ}

Авторы декларируют отсутствие явных и потенциальных конфликтов интересов, связанных с публикацией настоящей статьи.

\section{ЛИТЕРАТУРА / REFERENCES}

1. Алгоритмы специализированной медицинской помощи больным сахарным диабетом / Под редакцией И.И. Дедова, М.В. Шестаковой, А.Ю. Майорова. - 8 выпуск - М. : УП ПРИНТ, 2017. - 111 с. [Algorithms of specialized medical care for patients with diabetes mellitus. I.I. Dedov, M.V. Shestakova, A.Yu. Mayorov, editors. $8^{\text {th }}$ edition. Moscow: UP PRINT; 2017: 111 (in Russ.)].

2. Афиногенова А.Г., Даровская Е.Н. Микробные биопленки ран: состояние вопроса // Травматология и ортопедия России. - 2011. - Т. 61, № 3. C. 119-125. [Afinogenova A.G., Darovskaya E.N. Microbial biofilms of wounds: status of the issue. Travmatologiya i ortopediya Rossii. 2011; 61(3): 119-125 (in Russ.)].

3. Базлов С.Б., Шапошников В.И., Зорик В.В., Ралко C.Н. Пути повышения эффективности антибактериального лечения гнойно-некротических осложнений синдрома диабетической стопы (СДС) // Кубанский научный медицинский вестник. - 2010. - Т. 123, № 9. - C. 27-30. [Bazlov S.B.,
Shaposhnikov V.I., Zorik V.V., Ralko S.N. Ways of increase of efficiency of antibacterial treatment of is purulentnekrotic complications of the diabetic foot. $\mathrm{Ku}-$ banskiy nauchnyy meditsinskiy vestnik. 2010; 123(9): 27-30 (in Russ.)].

4. Белозериева Ю.П., Курлаев П.П., Есипов В.К., Грииенко B.A. Опыт лечения гнойно-некротических осложнений синдрома диабетической стопы с применением оригинальной хирургической методики на фоне целенаправленной антибиотикотерапии // Креативная хирургия и онкология. - 2014. № 3. - C. 67-70. [Belozertseva Yu.P., Kurlaev P.P., Esipov V.K., Gritsenko V.A. Experience in the treatment of purulent-necrotic complicationsof diabetic foot syndrome with the using of the original surgical method in the combination with a targeted antibiotic therapy. Kreativnaya khirurgiya i onkologiya. 2014; (3): 67-70 (in Russ.)].

5. Беляева О.А., Радзиховский А., Крыжевский В.В., Рыбянеч Ю.В., Уланович Л.И., Яковлева Э.И., Шендрик В.Г. Антимикробная терапия в комплексном лечении гнойно-некротических осложнений у пациентов с синдромом диабетической стопы // Хирургия Украины. - 2012. - Т. 44, № 4. C. 58-62. [Beliayeva O.A., Radzikhovskii A.P., Kryzhevskii V.V., Rybianets Yu.V., Ulanovich L.I., Yakovleva E.I., Shendrik V.G. Antimicrobial therapy in complex treatment of purulent necrotic complications in patients with diabetic foot syndrome. Khirurgiya Ukrainy. 2012; 44(4): 58-62 (in Russ.)].

6. Бенсман B.M. Хирургия гнойно-некротических осложнений диабетической стопы. Руководство для врачей. Второе переработанное и дополненное издание. - М. : ИД «Медпрактика», 2015. - 496 с. [Bensman V.M. Surgery of purulent-necrotic complications of diabetic foot. A guide for doctors. The second revised and updated edition. Moscow : ID “Medpraktika”; 2015: 496 (in Russ.)].

7. Блатун Л.А. Банеоцин ${ }^{\circledR}$ (порошок, мазь) - перспективы использования в комплексном хирургическом лечении гнойно-некротических поражений нижних конечностей у больных с синдром диабетической стопы // Раны и раневые инфекции. 2015. - T. 2, № 3. - C. 36-44. - DOI: 10.17650/24089613-2015-2-3-36-45. [Blatun L.A. Baneotsin ${ }^{\circledR}$ (powder, ointment) - perspective for use in complex surgical treatment of purulonecrotic diseases of the lower extremities in patients with diabetic foot syndrome. Rany i ranevyye infektsii. 2015; 2(3): 36-44 (in Russ.)].

8. Брискин Б.С., Прошин А.В., Полянский М.В., Лебедев B.B., Пироева К.Э. Антибактериальная терапия в комплексном лечении гнойно-некротических форм синдрома диабетической стопы // Хирургия. Приложение к журналу Consilium medicum. 2006. - № 1. - C. 16-19. [Briskin B.S., Proshin A.V., Polyanskiy M.V., Lebedev V.V., Piroyeva K.E. Antibacterial therapy in the complex treatment of purulentnecrotic forms of diabetic foot syndrome. Khirurgiya. Prilozheniye k zhurnalu Consilium medicum. 2006; (1): 16-19 (in Russ.)].

9. Бублик Е.В., Коршунова Ю.В., Крупинова Ю.А., Морозова О.A. Патогенетические аспекты местно- 
го лечения синдрома диабетической стопы. Новая альгинатная повязка Fibroclean Ag: какие преимущества? // Раны и раневые инфекции. - 2015. № 1. - C. 20-25. [Bublik E.V., Korshunova Yu.V., Krupinova Yu.A., Morozova O.A. Pathogenetic aspects of the wound care in diabetic patients.a new silver alginate dressing fibroclean ag: what are benefits? Rany i ranevyye infektsii. 2015; (1): 20-25 (in Russ.)].

10. Бухарин O.B. Персистенция патогенных бактерий. - М. : Медицина; Екатеринбург : УрО РАН, 1999. - 366 c. [Bukharin O.V. Persistence of pathogenic bacteria. Moscow : Meditsina; Ekaterinburg : UrO RAN; 1999: 366 (in Russ.)].

11. Бухарин О.В., Гинцбург А.Л., Романова Ю.М., ЭльРегистан Г.И. Механизмы выживания бактерий. М. : Медицина, 2005. - 367 с. [Bukharin O.V., Gintsburg A.L., Romanova Yu.M., El'-Registan G.I. Bacteria survival mechanisms. Moscow : Meditsina; 2005: 367 (in Russ.)].

12. Бухарин О.В., Курлаев П.П., Перунова Н.Б., Скоробогатых Ю.И. Экспериментальное изучение комбинации ципрофлоксацина с окситоцином на образование биопленок условно-патогенными бактериями // Журнал микробиологии, эпидемиологии и иммунобиологии. - 2010. - № 6. - С. 3-7. [Bukharin O.V., Kurlayev P.P., Perunova N.B., Skorobogat$y k h Y u . I$. Experimental study of the combination of ciprofloxacin with oxytocin on the formation of biofilms by conditionally pathogenic bacteria. Zhurnal mikrobiologii, epidemiologii i immunobiologii. 2010; (6): 3-7 (in Russ.)].

13. Выбор антибиотика при синдроме диабетической стопы. Международные стандарты. [Электронный peсурс] / Научный рецензент С.А. Шляпников. 2008. - Режим доступа: http://bonoesse.ru/blizzard/RPP/M/ENDO/dstopa.html, свободный (10.10.2018). [The choice of antibiotic for diabetic foot syndrome. International standards. [Electronic resource]. S.A. Shlyapnikov, scientific reviewer. - 2008. - Access mode: http://bonoesse.ru/blizzard/RPP/M/ENDO/dstopa.html, free (10/10/2018) (in Russ.)].

14. Гедзюн Р.В., Базлов С.Б. Влияние непрямого электрохимического окисления на резистентность микроорганизмов к антибиотикам у пациентов с осложненным формами диабетической стопы // Фундаментальные исследования. - 2004. - № 2. C. 123. [Gedzyun R.V., Bazlov S.B. The influence of indirect electrochemical oxidation on the resistance of microorganisms to antibiotics in patients with complicated forms of diabetic foot. Fundamental'nyye issledovaniya. 2004; (2): 123 (in Russ.)].

15. Гриценко B.A. Так ли чувствительны к метициллину метициллин-чувствительные Staphylococcus aureus (MSSA), как мы думаем? // Бюллетень Оренбургского научного центра УрО РАН. 2015. - № 3. - C. 1-13. [Gritsenko V.A. So whether methicillin-sensitive Staphylococcus aureus (MSSA) sensitive to methicillin, as we think? Byulleten' Orenburgskogo nauchnogo tsentra UrO RAN. 2015; (3): 1-13 (in Russ.)].

16. Давиденко О.П. Синдром диабетической стопы. Его роль и место в современной диабетологии (об- зор литературы) / Медицина и образование в Сибири. - 2014. - № 5. - С. 5. [Davidenko O.P. Syndrome of diabetic foot. Its role and place in modern diabetology (of literature review). Meditsina i obrazovaniye v Sibiri. 2014; (5): 5 (in Russ.)].

17. Дедов И.И. Сахарный диабет: развитие технологий в диагностике, лечении и профилактике (пленарная лекция) // Сахарный диабет - 2010. - № 3 C. 6-13. [Dedov I.I. Diabetes mellitus: development of technologies in diagnostics, treatment and prevention. Sakharnyy diabet. 2010; (3): 6-13. (in Russ.)].

18. Доброквашин С.В., Якупов Р.Р., Валеев А.З. Лечение больных с гнойно-некротическими осложнениями синдрома диабетической стопы // Практическая медицина. - 2011. - Т. 54, № 6. - С. 97-99. [Dobrokvashin S.V., Yakupov R.R., Valeev A.Z. Treatment of patients with purulent-necrotic complications syndrome of diabetic foot. Prakticheskaya meditsina. 2011; 54(6): 97-99 (in Russ.)].

19. Зубков М.Н. Внебольничные пневмонии: роль макролидов возрастает // Русский медицинский журнал. - 2006. - Т. 14, № 21. - С. 1545-1551. [Zubkov M.N. Community-acquired pneumonia: the role of macrolides. Russkiy meditsinskiy zhurnal. 2006; 14(21): 1545-1551 (in Russ.)].

20. Ивануса С.Я., Рисман Б.В., Иванов Г.Г. Современные представления о методиках оценки течения раневого процесса у больных с гнойно-некротическими осложнениями синдрома диабетической стопы // Вестник Российской военно-медицинской академии. - 2016. - Т. 54, № 2. - С. 190-194. [Ivanusa S.Ya., Risman B.V., Ivanov G.G. Modern views on evaluation methods of wound healing process in patients with pyo-necrotic complications of diabetic foot syndrome. Vestnik Rossiyskoy voyennomeditsinskoy akademii. 2016; 54(2): 190-194. (in Russ.)].

21. Курлаев П.П., Чернова О.Л., Киргизова С.Б. Влияние окситоцина, лазерного и электромагнитного излучения на персистентные свойства Staphylococcus aureus // Журнал микробиологии, эпидемиологии и иммунобиологии. - 2000. Прил. 4. - С. 62-64. [Kurlaev P.P., Chernova O.L., Kirgizova S.B. Interaction of oxytocin, laser and electromagnetic radiation on the persistence properties of Staphylococcus aureus. Zhurnal mikrobiologii, epidemiologii i immunobiologii. 2000; Suppl. 4: 62-64. (in Russ.)].

22. Лямин А.В., Боткин Е.А., Жестков А.В. Проблемы в медицине, связанные с бактериальными пленками // Клиническая микробиология и антимикробная химиотерапия. - 2012. - Т. 14, № 4. C. 268-275. [Lyamin A.V., Botkin E.A., Zhestkov A.V. Medical problems associated with bacterial biofilms. Klinicheskaya mikrobiologiya i antimikrobnaya khimioterapiya. 2012; 14(4): 268-275 (in Russ.)].

23. Мадянов И.В. Синдром диабетической стопы. Фокус на инфицированные язвы // Здравоохранение Чувашии. - 2016. - № 4. - C. 41-45. [Madyanov I.V. Diabetic foot syndrome. Focus on infected ulcers. Zdravookhraneniye Chuvashii. 2016; (4): 41-45 (in Russ.)]. 
24. Максимова Н.В. Синдром диабетической стопы: проблемы лечения и возможные пути решения // Актуальная эндокринология. - 2016. - № 3. C. 53-70. - DOI: 10.18508/endo4651 [Maximova N.V. Diabetic foot syndrome: treatment issues and possible solutions. Aktual'naya endokrinologiya. 2016; (3): 53-70 (in Russ.)].

25. Маркевич П.С., Даниленко С.Ю., Янкин А.В., Плеханов А.Н. Современные методы диагностики синдрома диабетической стопы // Acta biomedica scientifica. - 2012. - T. 88, № 6. - C. 151-155. [Markevich P.S., Danilenko S.J., Yankin A.V., Plekhanov A.N. The modern diagnostic methods of diabetic foot syndrome. Acta biomedica scientifica. 2012; 88(6): 151-155 (in Russ.)].

26. Привольнев В.В., Гусева Е.А., Каракулина Е.В. Обзор рекомендаций Американского общества по инфекционным заболеваниям по ведению пациентов с инфекциями диабетической стопы // Клиническая микробиология и антимикробная химиотерапия. - 2013. - Т. 15, № 1. - C. 14-22. [Privolnev V.V., Guseva E.A., Karakulina E.V.Review of the 2012 IDSA Guidelines on the Management of Diabetic Foot Infections. Klinicheskaya mikrobiologiya i antimikrobnaya khimioterapiya. 2013; 15(1): 14-22 (in Russ.)].

27. Светухин А.М., Земляной А.Б. Гнойно-некротические формы синдрома диабетической стопы // Consilium medicum. - 2002. - T. 4, № 10 . C. 537-544. [Svetukhin A.M., Zemlyanoy A.B. Purulent-necrotic forms of diabetic foot syndrome. Consilium medicum. 2002; 4(10): 537-544 (in Russ.)].

28. Способ выбора антибиотика или комбинации антибиотиков для лечения гнойных осложнений синдрома диабетической стопы: пат. № 2652449 РФ МПК G01N 33/487 / Курлаев П.П., Белозерцева Ю.П., Гриценко В.А. - заявл.: 01.08.2017; опубл.: 26.04.2018, Бюл. № 12. - 12 с. [The method of choosing an antibiotic or combination of antibiotics for the treatment of suppurative complications of diabetic foot syndrome: Pat. № 2652449 of the Russian Federation IPC G01N 33/487 / Kurlaev P.P., Belozertseva Yu.P., Gritsenko V.A. - stated: 08/01/2017; publ.: 04/26/2018, Bul. N 12. - 12 p. (in Russ.)].

29. Справочник Сэнфорда по противомикробной терапии: пер. с англ. / Д. Гилберт, Р. Мёллеринг мл., Дж. Элиопулос, Г. Чемберс, М. Сааг; под ред. А.Л. Спасокукотского. - Киев : Украинский медицинский вестник, 2012. - 272 с. [The Sanford Guide to Antimicrobial Therapy: Transl. from English / D.N. Gilbert, R.C. Moellering Jr, G.M. Eliopoulos, H.F. Chambers, M.S. Saag; A.L. Spasokukotsky, editor. - Kiev: Ukrainskiy meditsinskiy vestnik; 2012: 272 (in Russ.)].

30. Терехова Р.П., Пасхалова Ю.С., Складан Г.Е., Прудникова С.А., Блатун Л.А., Митии В.А. Изменения в структуре возбудителей хирургической инфекции у больных сахарным диабетом в зависимости от стратегии их лечения // Раны и раневые инфекции. - 2015. - Т. 2, № 3. - С. 22-29. - DOI: 10.17650/2408-9613-2015-2-3-22-29. [Terekhova R.P., Paskhalova Yu.S., Skladan G.E., Prudniko- va S.A., Blatun L.A., Mitish V.A. Changes in the structure of surgical infectious matter in patients with diabetes mellitus, depending on their treatment strategy. Rany i ranevyye infektsii. 2015; 2(3): 22-29 (in Russ.)].

31. Удовиченко О.В., Грекова Н.М. Диабетическая стопа. - М. : Практическая медицина, 2010. - 272 с. [Udovichenko O.V., Grekova N.M. Diabetic foot. Moscow : Prakticheskaya meditsina; 2010: 272 (in Russ.)].

32. Фадеев С.Б., Немцева Н.В. Формирование биопленок возбудителями хирургической инфекции мягких тканей // Журнал микробиологии, эпидемиологии и иммунобиологии. - 2009. - № 4. C. 114-117. [Fadeev S.B., Nemtseva N.V. Formation of biofilms by agents of surgical soft tissue infections. Zhurnal mikrobiologii epidemiologii i immunobiologii. 2009; (4): 114-117 (in Russ.)].

33. Хирургические инфекции кожи и мягких тканей. Российские национальные рекомендации. - 2-е переработанное и дополненное издание. - Москва, 2015. - 109 c. [Surgical infections of the skin and soft tissues. Russian national recommendations. $2^{\text {nd }}$ revised and enlarged edition. Moscow; 2015: 109 (in Russ.)].

34. Хирургические инфекции: руководство / под ред. И.А. Ерюхина, Б.Р. Гельфанда, С.А. Шляпникова. - СПб: Питер, 2003. - 864 с. [Surgical infections: a guide. I.A. Eryukhin, B.R. Gel'fand, S.A. Shlyapnikov, editors. - St. Petersburg : Piter; 2003: 864 (in Russ.)].

35. Чекмарева И.А., Митиш В.А., Паклина О.В., Блатун Л.А., Пасхалова Ю.С., Ушаков А.А., Терехова Р.П., Гордиенко Е.Н., Соков С.Л., Муньос Сепеда П.А., Качанжи А.П. Морфологическая оценка эффективности применения гидрохирургической системы VersaJet $\AA$ в сочетании с комбинированной антибактериальной терапией при лечении гнойно-некротических осложнений синдрома диабетической стопы с биопленочными формами бактерий // Раны и раневые инфекции. - 2015. - Т. 2, № 3. - C. 8-21. - DOI: 10.17650/2408-9613-2015-23-8-21 [Chekmareva I.A., Mitish V.A., Paklina O.V., Blatun L.A., Paskhalova Yu.S., Ushakov A.A., Terekhova R.P., Gordienko E.N., Sokov S.L., Mun'os Sepeda P.A., Kachanzhi A.P. Morphological evaluation of the effectiveness of hydrosurgical system VersaJet ${ }^{\circledR}$ in conjunction with combined antibiotic therapy in the treatment of necrotic complications of diabetic foot syndrome with biofilm forms of bacteria. Rany i ranevyye infektsii. 2015; 2(3): 8-21 (in Russ.)].

36. Челпаченко O.E., Зыкова Л.С. Влияние лекарственных препаратов на выражение персистентных свойств уропатогенных штаммов энтеробактерий // Журнал микробиологии эпидемиологии и иммунобиологии. - 1996. - № 3. - C. 84-86. [Chelpachenko O.E., Zykova L.S. The influence of drugs on the expression of persistent properties of uropathogenic strains of enterobacteria. Zhurnal mikrobiologii epidemiologii i immunobiologii. 1996; (3): 84-86 (in Russ.)].

37. Шаповал С.Д., Савон И.Л., Якунич А.Н., Максимова O.O. Резистентные и полирезистентные возбу- 
дители гнойно-некротических осложнений синдрома диабетической стопы // Новости хирургии. 2015. - T. 23, № 1. - C. 70-76. [Shapoval S.D., Savon I.L., Yakunich A.N., Maksimova O.O. Resistant and multiresistant agents of pyonecrotic complications of diabetic foot syndrome. Novosti Khirurgii. 2015; 23(1): 70-76 (in Russ.)].

38. Шутов Ю.М., Шутова М.З., Котрехова А.С. Комплексное местное лечение гнойно-некротических осложнений синдрома диабетической стопы в условиях поликлиники // Медицина и образование в Сибири. - 2015. - № 3. - С. 52. [Schedrin A.S., Shutova M.Z., Kotrekhova A.S. Complex local treatment of purulent necrotic complications of diabetic foot infection in the conditions of out-patient department. Meditsina i obrazovaniye v Sibiri. 2015; (3): 52 (in Russ.)].

39. Dang C., Prasad Y., Bouton A., Jude E.B. Methicillinresistant Staphylococcus aureus in the diabetic foot clinic: a worsening problem // Diabet Med. - 2003. Vol. 20, N 2. - P. 159-161.

40. del Pozo J.L., Patel R. The challenge of treating biofilm-associated bacterial infections // Clin Pharmacol Ther. - 2007. - Vol. 82, N 2. - P. 204-209. - DOI: 10.1038/sj.clpt.6100247.

41. Edmonds M.E. The diabetic foot, $2003 / /$ Diabetes Metab Res Rev. - 2004. - Vol. 20, Suppl 1. P. 9-12. - DOI: 10.1002/dmrr.458.

42. Jude E.B., Oyibo S.O., Chalmers N., Boulton A.J. Peripheral arterial disease in diabetic and nondiabetic patients: a comparison of severity and outcome // Diabetes Care. - 2001. - Vol. 24, N 8. - P. 1433-1437.

43. Karchmer $A . W$. Microbiology and treatment of diabeticfoot infections. In: The Diabetic Foot, 2nd edn. / A. Veves, J.M.Giurini, F.W. Logerfo (eds.). - Boston : Humana Press, 2006. - P. 255-268.
44. Lesens O., Desbiez F., Vidal M., Robin F., Descamps S., Beytout J., Laurichesse H., Tauveron I. Culture of per-wound bone specimens: a simplified approach for the medical management of diabetic foot osteomyelitis // Clin Microbiol Infect. - 2011. - Vol. 17, N 2. - P. 285-291. - DOI: 10.1111/j.14690691.2010.03194.x.

45. Lipsky B.A., Hoey C. Topical antimicrobial therapy for treating chronic wounds // Clin Infect Dis. - 2009. Vol. 49, N 10. - P. 1541-1549. - DOI: $10.1086 / 644732$.

46. Lipsky B.A., Berendt A.R., Deery H.G., Embil J.M., Joseph W.S., Karchmer A.W., LeFrock J.L., Lew D.P., Mader J.T., Norden C., Tan J.S.; Infectious Diseases Society of America. Diagnosis and treatment of diabetic foot infections // Clin Infect Dis. - 2004. - Vol. 39, N 7. - P. 885-910. - DOI: $10.1086 / 424846$.

47. Olson M.E., Ceri H., Morck D.W., Buret A.G., Read R.R. Biofilm bacteria: formation and comparative susceptibility to antibiotics // Can J Vet Res. 2002. - Vol. 66, N 2. - P. 86-92.

48. Percival S.L., Slon W., Linton S., Okel T., Corum L., Thomas J.G. The antimicrobial efficacy of a silver alginate dressing against a broad spectrum of clinically relevant wound isolates // Int Wound J. - 2011. Vol. 8, N 3. - P. 237-243. - DOI: 10.1111/j.1742481X.2011.00774.x.

49. Percival S.L., Thomas J.G., Williams D.W. Biofilms and bacterial imbalances in chronic wounds: antiKoch // Int Wound J. - 2010. - Vol. 7, N 3. - P. 169175. - DOI: 10.1111/j.1742-481X.2010.00668.x.

50. Ryder M.A. Catheter-related Infections: It's all about biofilm [Electronic resource] // Topics in Advanced Practice Nursing Journal. - 2005. - Vol. 5, N 3. - Access mode: medscape.com/viewarticle/508109, free (24/12/2017). 